Natural Hazards and Earth System Sciences (2002) 2: 217-220

(C) European Geosciences Union 2002

(E) Natural Hazards

\title{
The calibration of an avalanche mathematical model using field data
}

\author{
V. Blagovechshenskiy ${ }^{1}$, M. Eglit ${ }^{2}$, and M. Naaim ${ }^{3}$ \\ ${ }^{1}$ Institute of Geography, Kazakhstan \\ ${ }^{2}$ Moscow State University, Russia \\ ${ }^{3}$ CEMAGREF, France
}

Received: 20 September 2001 - Revised: 11 January 2002 - Accepted: 14 January 2002

\begin{abstract}
The experience of calibrating Eglit's avalanche model using data about the avalanche travel distance lengths and velocity data from the Zailiyskiy Alatau range (Kazakhstan) is discussed. Empirical equations are proposed that describe the dependence of the friction coefficients on the avalanche volume and type.
\end{abstract}

\section{Introduction}

A number of different mathematical models of avalanche motion have been developed (see, e.g. Harbitz, 1998). The practical use of the models is limited by the uncertainty of the model coefficients and initial data upon snow conditions and avalanche volumes. The way of solving this problem is by adaptation of models to regional conditions. Data from real avalanches can be used for this purpose. The experience of adapting Eglit's model to the conditions of the Zailiyskiy Alatau range in Kazakhstan is described in the paper.

The Zailiyskiy Alatau range belongs to Tian-Shan Mountains. Two typical avalanche sites in the Malaya Almatinka valley are studied here. Data from 9 artificial avalanches released by explosives were considered. Four dry avalanches were measured at avalanche site No. 17 and six wet at avalanche site No. 21.

Avalanche site No. 17 is a free slope with northern aspect. The area of the starting zone is $8000 \mathrm{~m}^{2}$ and its steepness is $37^{\circ}$. The avalanche track has an average steepness equal to $30^{\circ}$. The runout zone is at valley bottom with a steepness of $12-20^{\circ}$. The altitude of the starting zone is $2750 \mathrm{~m}$. The avalanche drop height is about $450 \mathrm{~m}$ and the path length is about $1000 \mathrm{~m}$. Avalanche site No. 21 is a basin with a starting zone area equal to $90000 \mathrm{~m}^{2}$. The altitude of the starting zone is $2750 \mathrm{~m}$ with a northerly aspect and a steepness of $37^{\circ}$. The avalanche track is a deep gully with a steepness of $15-25^{\circ}$. The runout zone is located at the lower part of the gully and has steepness $9-12^{\circ}$. The maximum avalanche

Correspondence to: V. Blagovechshenskiy (ingeo@mail.kz) drop height is $1000 \mathrm{~m}$ and the path length is $3500 \mathrm{~m}$. The surfaces of both avalanche sites are smooth and grassy with rare small bushes. All measured avalanches moved over an old snow surface and the track roughness in all cases was low and approximately the same.

\section{The field data}

Avalanche volume, velocity and flow height were measured. Avalanche volume was determined as a product of the starting zone area and the snow fracture height. The starting zone area and the travel distance were measured from 1:25000 scale maps. The snow fracture height was measured in situ. All avalanches were filmed by video camera with speed of 24 frames per second. The velocities were measured by finding the motion time between fixed points. The stop-frame was used for measuring the flow height. The errors of measurements were about $1 \mathrm{~m} / \mathrm{s}$ for the avalanche velocity and about $0.5 \mathrm{~m}$ for the flow height. The measured avalanche parameters are given in Table 1 . The measurements were made at a middle part of the avalanche tracks, where the avalanches were fully developed. So, the measured velocities and flow heights were close to maximum.

\section{The mathematical model}

The averaged over the cross section continuum model developed by $M$. Eglit has been used for calculation of the avalanche travel distance, $l$, velocity, $v$, and flow height, $h$. The basic assumptions of the model are described in Eglit (1968). The equations and the numerical method used can be found in Mironova and Eglit (1988) and in Eglit (1998). The basic system of equations is written in the form:

$$
\begin{aligned}
& \frac{\partial S}{\partial t}+\frac{\partial S v}{\partial x}=0 \\
& \frac{\partial S v}{\partial t}+\frac{\partial S v^{2}}{\partial x}+\frac{\partial F_{2}}{\partial x}=S g \sin \alpha+F_{3}-v F_{1} .
\end{aligned}
$$


Table 1. Field measured avalanche parameters

\begin{tabular}{lllllll}
\hline $\begin{array}{l}\text { No. } \\
\text { site }\end{array}$ & $\begin{array}{l}\text { Avalanche } \\
\text { type }\end{array}$ & $\begin{array}{l}\text { Avalanche } \\
\mathrm{m}^{3}\end{array}$ & $\begin{array}{l}\text { Volume } \\
\mathrm{m}\end{array}$ & $\begin{array}{l}\text { Travel distance } \\
\mathrm{m} / \mathrm{s}\end{array}$ & $\begin{array}{l}\text { Velocity } \\
\mathrm{m}\end{array}$ & $\begin{array}{l}\text { Flow height } \\
\mathrm{m}\end{array}$ \\
\hline 1 & 17 & dry & 2000 & 830 & 15 & 2 \\
2 & 17 & dry & 5000 & 870 & 20 & 4 \\
3 & 17 & dry & 8000 & 940 & 25 & 6 \\
4 & 17 & dry & 12000 & 1000 & 30 & 10 \\
5 & 21 & wet & 5000 & 1320 & 5 & 2 \\
6 & 21 & wet & 10000 & 1800 & 5 & 4 \\
7 & 21 & wet & 50000 & 2300 & 11 & 6 \\
8 & 21 & wet & 100000 & 2830 & 10 & 8 \\
9 & 21 & wet & 130000 & 3020 & 12 & 10 \\
\hline
\end{tabular}

Here, $x$ is a longitudinal coordinate, $S$ is the flow cross section, $\alpha$ is the slope angle, $F_{1}, F_{2}, F_{3}$ are connected with friction, total pressure in a cross section and the pressure at the channel side walls, respectively. The boundary conditions for this system are the conditions at the leading front

$S(w-v)=S_{0} w \rho_{0}, \quad S_{0} w \rho_{0} v=\rho F_{2} S-\sigma^{*} S_{0}$ at $x=x_{f}$, and the conditions at the back boundary $S=0, v=0$ at $x=0$. Here, $w$ is the front velocity, $\rho$ and $\rho_{0}$ are the densities of the avalanche flow and snow cover in front of it, respectively, $\rho^{*}$ is the strength of the snow cover and $S_{0}$ is the cross-section area of the snow cover involved into the motion. In this paper, the shape of the avalanche track cross section is assumed to be trapezoidal. In this case,

$S=B h+\frac{1}{2} h^{2}\left(\tan \beta_{1}+\tan \beta_{2}\right)$,

$F_{2}=\frac{1}{2} g h^{2} \cos \alpha B+\frac{1}{2} g h^{3} \cos \alpha\left(\tan \beta_{1}+\tan \beta_{2}\right)$,

$F_{3}=\frac{1}{2} g h^{2} \cos \alpha \frac{d B}{d x}+\frac{1}{6} g h^{3} \cos \alpha \frac{d}{d x}\left(\tan \beta_{1}+\tan \beta_{2}\right)$.

Friction force is defined by the following formulae:

$F_{1}=k|v| L+\mu g \cos \alpha \frac{B+L}{2|v|}$ at $h \leq h^{*} \equiv \frac{\tau^{*}}{\rho \mu g \cos \alpha}$,

$F_{1}=k|v| L+\mu g \cos \alpha \frac{h^{*}\left(2 L-h^{*}\left(\cos ^{-1} \beta_{1}+\cos ^{-1} \beta_{2}\right)\right)}{2|v|}$,

at $h>h^{*}$,

$L=B+h\left(\cos ^{-1} \beta_{1}+\cos ^{-1} \beta_{2}\right)$.

Here, $B$ is the bottom width of the channel, $\beta_{1}$ and $\beta_{2}$ are the side walls slope angles, $k$ is the hydraulic (turbulent) friction coefficient, $\mu$ is the dry friction coefficient, $\tau^{*}$ is the shear strength of the snow cover, $h^{*}$ is the value of the flow height at which the shear stress connected with the dry friction is equal to $\tau^{*}$. The Coulomb friction law is modified by introducing an upper limit for the dry friction (Grigorian, 1979), i.e. it is assumed that the shear stress on the interface between the avalanche and the sliding surface cannot be larger than the shear strength $\tau^{*}$ for the bottom material. The following data are needed to calculate the avalanche motion:

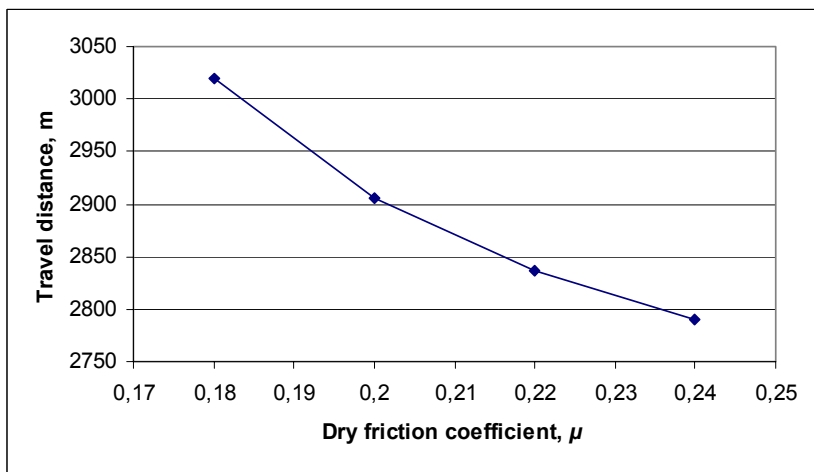

Fig. 1. The dependence of the calculated avalanche travel distance on the dry friction coefficient for the wet avalanche No. $8, k=0.08$.

(1) the avalanche site relief (the steepness, the bottom width of the avalanche path and the steepness of side walls), (2) the snow height at the starting zone and along the avalanche path, (3) the initial avalanche volume, (4) the dry friction coefficient, (5) the turbulent friction coefficient, (6) the ratio $\tau^{*} / \rho$. The results of calculation are the distributions of the velocity and the flow height along the avalanche body, the avalanche travel distance and the avalanche snow deposition depth.

\section{Calibration of the friction coefficients}

The initial volumes for avalanche simulations were chosen equal to those for the real avalanches. In general, the model takes the snow entrainment along the path into account according to the conditions at the leading front written above. In this paper, the motion without the snow entrainment was simulated, so the avalanche volume did not change from start to finish. For each avalanche 16 calculations with four different values of $\mu$ and $k$ were made. The value ranges of $\mu$ and $k$ changed from one avalanche to another so that the real avalanche parameters were located inside the calculated avalanche parameter ranges. For example, for the avalanche No. 8 , values of $\mu$ were $0.18,0.20,0,22,0,24$ and the val- 
Table 2. The calibrated (1) and measured (2) values of turbulent friction coefficient $k$ and dry friction coefficient $\mu$ and the calculated (1) and measured (2) avalanche parameters

\begin{tabular}{|c|c|c|c|c|c|c|c|c|c|c|}
\hline \multirow[t]{2}{*}{ No. } & \multicolumn{2}{|c|}{$k$} & \multicolumn{2}{|c|}{$\mu$} & \multicolumn{2}{|c|}{ Travel distance, $\mathrm{m}$} & \multicolumn{2}{|c|}{ Velocity, m/s } & \multicolumn{2}{|c|}{ Flow height, $\mathrm{m}$} \\
\hline & 1 & 2 & 1 & 2 & 1 & 2 & 1 & 2 & 1 & 2 \\
\hline 1 & 0.0063 & 0.006 & 0.49 & 0.48 & 820 & 830 & 13 & 15 & 1.2 & 3 \\
\hline 2 & 0.0046 & 0.005 & 0.44 & 0.46 & 860 & 870 & 19 & 20 & 1.5 & 4 \\
\hline 3 & 0.0033 & 0.003 & 0.42 & 0.42 & 940 & 940 & 23 & 25 & 1.7 & 6 \\
\hline 4 & 0.0022 & 0.002 & 0.39 & 0.38 & 990 & 1000 & 40 & 35 & 2.4 & 10 \\
\hline 5 & 0.091 & 0.090 & 0.34 & 0.35 & 1330 & 1320 & 3.0 & 5.0 & 1.0 & 2 \\
\hline 6 & 0.084 & 0.080 & 0.32 & 0.30 & 1820 & 1800 & 5.0 & 5.0 & 3.0 & 4 \\
\hline 7 & 0.067 & 0.070 & 0.25 & 0.25 & 2310 & 2300 & 10.0 & 11.0 & 6.0 & 6 \\
\hline 5 & 0.061 & 0.061 & 0.23 & 0.23 & 2835 & 2830 & 7.5 & 8 & 8.2 & 8 \\
\hline 6 & 0.057 & 0.055 & 0.21 & 0.21 & 3022 & 3020 & 9.7 & 10 & 9.8 & 10 \\
\hline
\end{tabular}

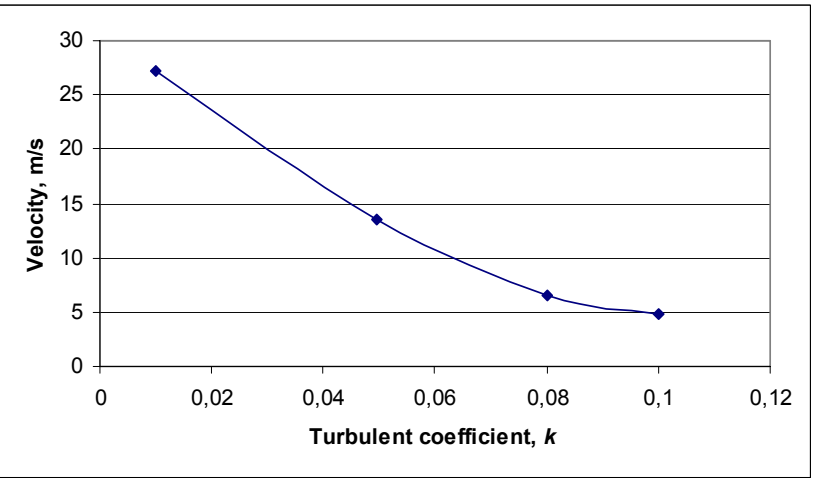

Fig. 2. The dependence of the calculated avalanche velocity on turbulent friction coefficient for the wet avalanche No. $8, \alpha=0.22$.

ues of $k$ were $0.01,0.05,0.08$, and 0.10 . On the whole, for all avalanches, $\mu$ varied from 0.15 to 0.50 and $k$ varied from 0.002 to 0.10 . The value $\tau^{*} / \rho=10 \mathrm{~m}^{2} / \mathrm{s}^{2}$ was assumed for all avalanches. This value was obtained by Mironova for avalanches at Caucasus (Volodicheva et al., 1990).

The values of $\mu$ and $k$ were determined in the following way. The results of calculations of the avalanche travel distance, $l$, at constant $k$ and different $\mu$ were studied. The diagram of the dependence of $l$ on $\mu$ was plotted (Fig. 1). The value of $\mu$ providing the coincidence of the calculated and measured $l$ was determined using this diagram. For example, the dependence $l=f(\mu)$ at $k=0.08$ for the wet avalanche is given in Fig. 1. The real travel distance is $2830 \mathrm{~m}$, and the corresponding $\mu$ value is 0.22 . The same travel distance is obtained with different pairs of $\mu$ and $k$, e.g. $k=0.06$, $\mu=0.226$ and $k=0.05, \mu=0.23$.

In a similar way the dependence of the avalanche velocity, $v$, at the control point on the turbulent friction coefficient at constant dry friction coefficient was obtained. The dependence $v=f(k)$ for the avalanche No. 8 with $\mu=0.22$ is given in the Fig. 2. The real velocity is $10 \mathrm{~m} / \mathrm{s}$ and the corresponding $k$ value is 0.062 . The same calculated velocity can be obtained, e.g. with $\mu=0.18, k=0.072$ and $\mu=0.24$,

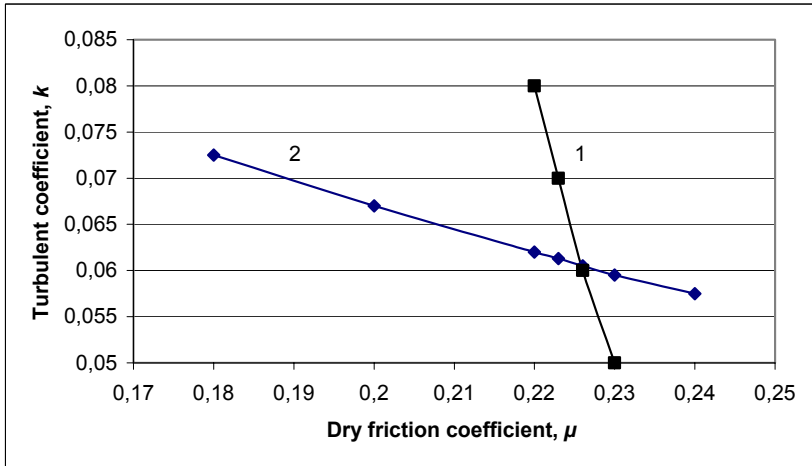

Fig. 3. The values of the turbulent friction coefficient and the dry friction coefficient which give the real value of the avalanche travel distance (curve 1) and the given value of the avalanche velocity (curve 2) for the avalanche No. 8.

$k=0.057$. The two dependencies $k=f(\mu)$, providing the coincidence of calculated and measured values of $l$ and $v$, were plotted. The meeting point of these curves determines the coefficients for the avalanche in consideration (Fig. 3). In the given case, they are $\mu=0.227, k=0.061$.

The values of $\mu$ and $k$, obtained by this way, are the measured ones. The results of their determination are given in Table 2. As the approximation of these results, the following calibrated values of $\mu$ and $k$ are proposed according to the avalanche type and volume:

for dry avalanches: $\mu=-0.132 \log V+0.941, k=$ $-0.0055 \log V+0.0251$,

for wet avalanches: $\mu=-0.0907 \log V+0.679, k=$ $-0.0231 \log V+0.176$.

\section{Conclusion}

It is worth mentioning that the turbulent friction coefficient, $k$, at Eglit's model corresponds to the coefficient $\xi$ at Voellmy's model (Voellmy, 1955) as $k=g / \xi$. The Swiss Guideline for calculation of avalanche runout distance (Salm 
et al., 1990) recommends the values of the dry friction coefficients, $\mu$, from 0.155 to 0.30 and the values of the turbulent friction coefficient, $\xi$, from 400 to $1000 \mathrm{~m} / \mathrm{s}^{2}$. For hydrauliccontinuum avalanche models, Barbolini et al. (2000) had obtained the values of $\mu$ from 0.13 to 0.40 and the values of $\xi$ from 1000 to $4500 \mathrm{~m} / \mathrm{s}^{2}$ in calculations of five large avalanches at European sites. In Eglit's model, the calibrated values of $\mu$ vary from 0.21 to 0.49 and calibrated values of $\xi$ vary from 170 to $4460 \mathrm{~m} / \mathrm{s}^{2}$ for avalanches with volumes of different orders in Zailiiskii Alatau.

The simulations of avalanche motion have been made with volumes equal to measured ones and with the calibrated dry friction and turbulent coefficients obtained by the proposed dependencies of $\mu$ and $k$ on $V$. The results are given in Table 2. The data in Table 2 show that the mathematical simulation of avalanche motion using Eglit's model with the calibrated coefficients has a very good coincidence with field data for the avalanche travel distance and velocities both at the avalanche sites No. 21 and 17. The calculated flow heights of wet avalanches are also very close to real ones. This fact can be treated as a confirmation of the applicability of the model to wet avalanches, since the model's coefficient values were obtained without comparison of calculated and real flow heights. In contrast, the measured flow heights of dry avalanches are much larger than simulated ones. It may mean that the air entrainment should be taken into account for the modeling of flow heights of dry avalanches.

Acknowledgements. This work was supported by INTAS, project INTAS 97-41590 and RFBR, project 99-01-01153. The authors thank the editorial assistant K. Gänger and the reviewer Ch. Keylock for valuable comments and suggestions.

\section{References}

Barbolini, M., Gruber, U., Keylock, C. J., Naaim, M., and Savi, F.: Application of statistical and hydraulic-continuum dense-snow avalanche models to five real European sites. Cold Reg. Sci. Techn. 31, 133-149, 2000.

Eglit, M. E.: Theoretical approaches to the calculation of the motion of snow avalanches. Itogi nauki. Moscow, VINITI, 60-97 (Russian). English translation in Glaciological Data, Report GD-16 (1974), 1968.

Eglit, M. E.: Mathematical modeling of dense avalanches. In: Proceedings of the Anniversary Conference 25 Years of Snow Avalanche Research, (Ed) Hestnes, E., Voss, 12-16 May 1998. Oslo, Norwegian Geotechnical Institute, Publication 203, 15-18, 1998.

Grigorian, S. S.: A new law of friction and mechanism for largescale slag heaps and landslides. Dokl. Akad. Nauk SSSR, 244, 846-849. English translation in Soviet Phys. Dokl. 24, 1979.

Harbitz, C. (Ed): A survey of computational models for snow avalanche motion. Deliverable No. 4 of the EU 4th Framework SAME research program. Norwegian Geotechnical Institute, 1998.

Mironova, E. M. and Eglit, M. E.: Paket prikladnih programm dlya chislennogo modelirovaniya snezhnih lavin, seley i vodnih potokov (A package of computational codes for simulation of snow avalanches, mudflows and water flows). (Russian with English summary). Data of Glaciological Studies, 63, 161-165, 1988.

Salm, B., Burkard, A., and Gubler, H. U.: Berechnung von Fliesslawinen: eine Anleitung für Praktiker mit Beispielen. Mitteilungen des Eidgenössischen Instituts für Schnee- und Lawinenforschung, Nr. 47. Davos, 1990.

Voellmy, A.: Über die Zerstörungskraft von Lawinen. Schweiz, Bauzeitung, 73, 159-165, 212-217, 246-249, 280-285, 1955.

Volodicheva, N. A., Zolotarev, E. A., Efremov, I. Yu., Mironova, E. M., and Oleinikov, A. D.: Application of numerical modeling to the description of snow avalanche motion. (Russian with English summary), Data of Glaciological Studies, 69, 19-24, 1990. 